\title{
Modeling and Analysis
}

\section{Techno-economic and life-cycle}

\section{assessments of small-scale}

\section{biorefineries for isobutene and}

xylo-oligosaccharides production:

a comparative study in Portugal and Chile

Tiago F. Lopes $₫$, Florbela Carvalheiro, Luís C. Duarte, and Francisco Gírio, Unidade de Bioenergia, Laboratório Nacional de Energia e Geologia, I.P., Lisbon, Portugal

Julián A. Quintero, Department of Chemical Engineering, Universidad de Santiago de Chile, Santiago, Chile

Germán Aroca, School of Biochemical Engineering, Pontificia Universidad Católica de Valparaíso, Valparaíso, Chile

Received January 21 2019; Revised June 11 2019; Accepted June 12 2019;

View online July 8, 2019 at Wiley Online Library (wileyonlinelibrary.com);

DOI: 10.1002/bbb.2036; Biofuels, Bioprod. Bioref. 13:1321-1332 (2019)

Abstract: This work presents a comparative simulation study involving the techno-economic and environmental assessment of lignocellulosic-based small-scale biorefineries, integrated with a piggery waste-based anaerobic digestion platform (ADB), located in Portugal and Chile. Two main products are obtained: isobutene and xylo-oligosaccharides (XOS). The bioproduction of isobutene using a genetically engineered organism (Escherichia coli), coupled with the removal and purification of high addedvalue XOS, obtained after a feedstock hydrothermal pre-treatment, was evaluated. Two lignocellulosic agricultural wastes were used: corn stover in the Portuguese case study and wheat straw in Chilean case study. Both processes were simulated using the Aspen Plus modeling software tool, while the Aspen Process Economic Analyzer was used to carry out the economic evaluation. The simulation results were validated with experimental data from the laboratory and the literature. An economic assessment was performed considering the different locations of both biorefineries. A life-cycle analysis (LCA) was also applied to evaluate the differences in environmental impacts on both locations. The results showed that the isobutene / XOS biorefinery concept was economically viable in both Portugal and Chile, mainly due to the high market value of XOS. The biorefinery has lower production costs for isobutene and XOS (1 US\$/kg of isobutene and 1.18 US\$/kg of XOS) when located in Portugal, as compared with Chile (1.14 